\title{
Good Oral Health and Diet
}

\author{
G. A. Scardina and P. Messina \\ Section Oral Sciences, Department of Surgical and Oncological Disciplines, University of Palermo, Via Del Vespro 129, \\ 90127 Palermo, Italy
}

Correspondence should be addressed to G. A. Scardina, scardina@odonto.unipa.it

Received 29 June 2011; Revised 16 September 2011; Accepted 21 October 2011

Academic Editor: David A. Spratt

Copyright ( 2012 G. A. Scardina and P. Messina. This is an open access article distributed under the Creative Commons Attribution License, which permits unrestricted use, distribution, and reproduction in any medium, provided the original work is properly cited.

\begin{abstract}
An unhealthy diet has been implicated as risk factors for several chronic diseases that are known to be associated with oral diseases. Studies investigating the relationship between oral diseases and diet are limited. Therefore, this study was conducted to describe the relationship between healthy eating habits and oral health status. The dentistry has an important role in the diagnosis of oral diseases correlated with diet. Consistent nutrition guidelines are essential to improve health. A poor diet was significantly associated with increased odds of oral disease. Dietary advice for the prevention of oral diseases has to be a part of routine patient education practices. Inconsistencies in dietary advice may be linked to inadequate training of professionals. Literature suggests that the nutrition training of dentists and oral health training of dietitians and nutritionists is limited.
\end{abstract}

\section{Introduction}

The concept of oral health correlated to quality of life stems from the definition of health that the WHO gave in 1946. Health is understood to be "a state of complete physical, mental, and social well-being and not merely the absence of disease or infirmity". The programs for the prevention of oral diseases concern teaching about oral hygiene and healthy eating, fluoride prophylaxis, periodic check-ups, sessions of professional oral hygiene, and secondary prevention programs [1]. The term "bionutrition" refers to the important interactions which exist between diet, use of nutrients, genetics, and development. This term emphasizes the role of nutrients in maintaining health and preventing pathologies at an organic, cellular, and subcellular level [2].

There exists a biunique relationship between diet and oral health: a balanced diet is correlated to a state of oral health (periodontal tissue, dental elements, quality, and quantity of saliva).

Vice versa an incorrect nutritional intake correlates to a state of oral disease [3-6].

\section{Diet and the Development of the Oral Cavity}

Diet influences the development of the oral cavity: depending on whether there is an early or late nutritional imbalance, the consequences are certainly different. In fact, an early nutritional imbalance influences malformations most. Moreover, the different components of the stomatognathic apparatus undergo periods of intense growth alternated with periods of relative quiescence: it is clear that a nutritional imbalance in a very active period of growth will produce greater damage [3].

A shortage of vitamins and minerals in the phase before conception influences the development of the future embryo, influencing dental organogenesis, the growth of the maxilla, and skull/facial development $[1,2]$.

An insufficient supply of proteins can lead to $[3,4]$ the following:

(i) atrophy of the lingual papillae,

(ii) connective degeneration,

(iii) alteration in dentinogenesis,

(iv) alteration in cementogenesis,

(v) altered development of the maxilla,

(vi) malocclusion,

(vii) linear hypoplasia of the enamel. An insufficient supply of lipids can lead to $[5,6]$ the following:

(i) inflammatory and degenerative pathologies, 


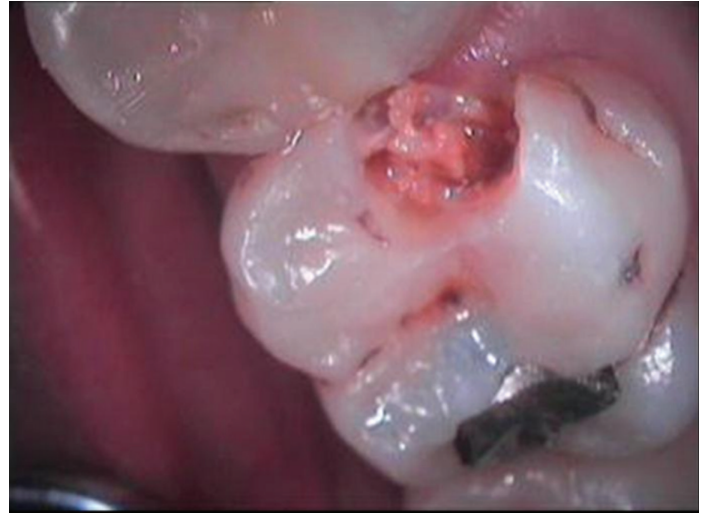

Figure 1: Caries of the teeth.

(ii) parotid swelling—hyposalivation,

(iii) degeneration of glandular parenchyma,

(iv) altered mucosal trophism.

An insufficient supply of carbohydrates can lead to the following:

(i) altered organogenesis,

(ii) influence of the metabolism on the dental plaque,

(iii) caries,

(iv) periodontal disease.

Diet influences the health of the oral cavity, conditioning the onset of caries, the development of the enamel, the onset of dental erosion, the state of periodontal health, and of the oral mucous in general.

\section{Caries}

Caries is a demineralization of the inorganic part of the tooth with the dissolution of the organic substance due to a multifactorial etiology. The demineralization of the enamel and of the dentine is caused by organic acids that form in the dental plaque because of bacterial activity, through the anaerobic metabolism of sugars found in the diet [7].

Demineralization occurs when the organic acids produced increase the solubility of the calcium hydroxyapatite that is present in the hard tissue of teeth (Figure 1).

The development of caries requires the presence of sugars and bacteria but it is influenced by the susceptibility of the teeth, by the type of bacteria, and by the quantity and quality of the salivary secretion.

Saliva is supersaturated with calcium and phosphate with a $\mathrm{pH}$ equal to 7 , a level that favours remineralization. When acid stimulation is too strongdemineralization prevails until the formation of a carious lesion [8].

Very low levels of dental caries are found in isolated communities with a traditional lifestyle and low consumption of sugars [7-9]. As soon as economic conditions improve and the quantity of sugars and other fermentable carbohydrates increases in the diet, a notable increase in dental caries is noticed. This has been seen in the Inuit of Alaska and in populations in Ethiopia, Ghana, Nigeria, Sudan, and the islands of Tristan da Cunha and Sant'Elena [7-9].

A Vipeholm study in Sweden between 1945 and 1953 in an institute for the mentally ill underlined the correlation between caries and the intake of sugary food of variable viscosity. If the sugar was ingested up to a maximum of 4 times a day only during meals, it had little effect on the increase of caries, even if this occurred in great quantities; the increase in the frequency of consumption of sugar between meals was associated to an increase in caries; when they no longer ate foods rich in sugar, the incidence in the formation of caries diminished [10].

The types of sugar ingested through diet also influence the onset of illness. In fact, studies on the $\mathrm{pH}$ of the dental plaque have shown that lactose produces less acidity in comparison to other sugars.

A 1970 Finnish study on a supervised dietary change revealed that, in an adult population, the almost total substitution of sucrose in the diet with xylitol determines a $85 \%$ reduction in caries over a 2-year period; its mechanism of action resides in the inhibition of the growth of Streptococcus mutans, the most important microorganism responsible for the formation of caries [11].

Diet can be a good ally in the prevention of caries [12].

(i) Increase in the consumption of fibres: diminution of the absorption of sugars contained in other food.

(ii) Diets characterized by a ratio of many amides/little sugar have very low levels of caries.

(iii) Cheese has cariostatic properties.

(iv) Calcium, phosphorus and casein contained in cow milk inhibit caries.

(v) Wholemeal foods have protective properties: they require more mastication, thus stimulating salivary secretion.

(vi) Peanuts, hard cheeses, and chewing gum are good gustative/mechanical stimulators of salivary secretion.

(vii) Black tea extract increases the concentration of fluorine in the plaque and reduces the cariogenicity of a diet rich in sugars.

(viii) Fluorine.

Fluorine remains a milestone in the prevention and in the control of dental caries. It has a preeruptive mechanism of action (incorporation in the enamel during amelogenesis) and a posteruptive mechanism (topical action). Fluorine reduces caries by $20-40 \%$ in children, but it does not entirely eliminate them: even when fluorine is used, the association between the intake of sugars and caries continues to be present all the same [13].

Diet also influences the qualitative characteristics of salivary secretion. The secretive proteins (mucines) represent an important barrier against the reduction of humidity, against the physical and chemical penetration of irritants and against bacteria [14]. 


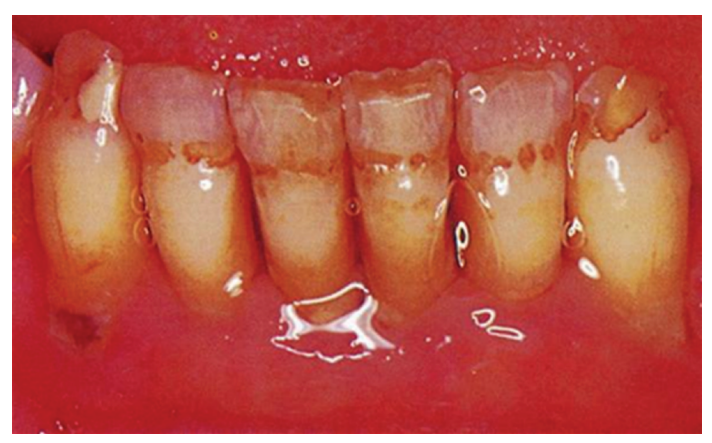

FIGURE 2: Hypoplasia and pits on the surface of the enamel correlate to a lack of vitamin A.

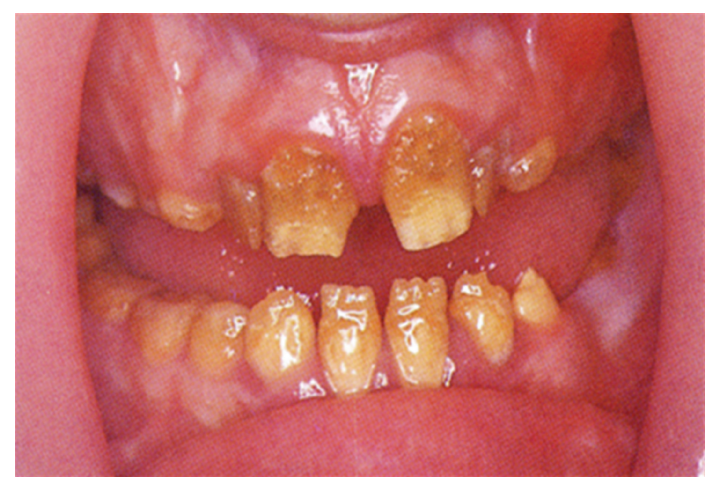

FIGURE 3: Hypoplasia on the surface of the enamel correlate to a lack of vitamin D.

The synthesis of glycoproteins requires vitamin A. In an imbalanced diet, there is a reduction in the content of mucines with the consequent risks for oral health (Caries!!).

\section{Development of the Enamel}

Teeth in a preeruptive phase are influenced by the nutritional state. A lack of vitamins D and A and protein-energy malnutrition have been associated to hypoplasia of the enamel and atrophy of the salivary glands, conditions that determine a greater susceptibility to caries. Some hypoplasia and pits on the surface of the enamel correlate to a lack of vitamin A (Figure 2); a lack of vitamin D is associated to the more diffused hypoplastic forms (Figure 3). The structural damage can testify to the period in which the lack of nutrition occurred [15].

\section{Dental Erosion}

"Dental erosion is the progressive irreversible loss of dental tissue that is chemically corroded by extrinsic and intrinsic acids through a process that does not involve bacteria...."

Extrinsic Acids Derived from Diet. They citric, phosphoric, ascorbic, malic, tartaric, and carbonic acids that are found in fruit, in fruit juices, in drinks, and in vinegar.

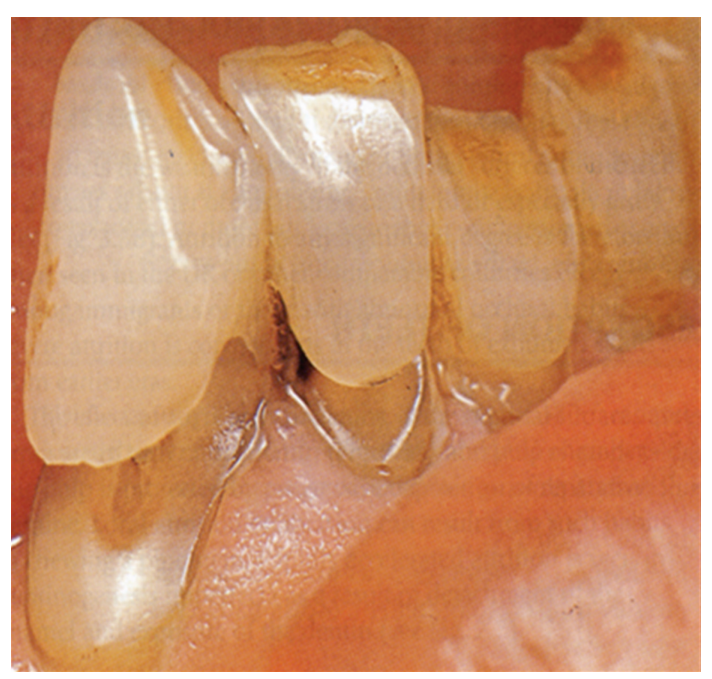

Figure 4: Dental Erosion.

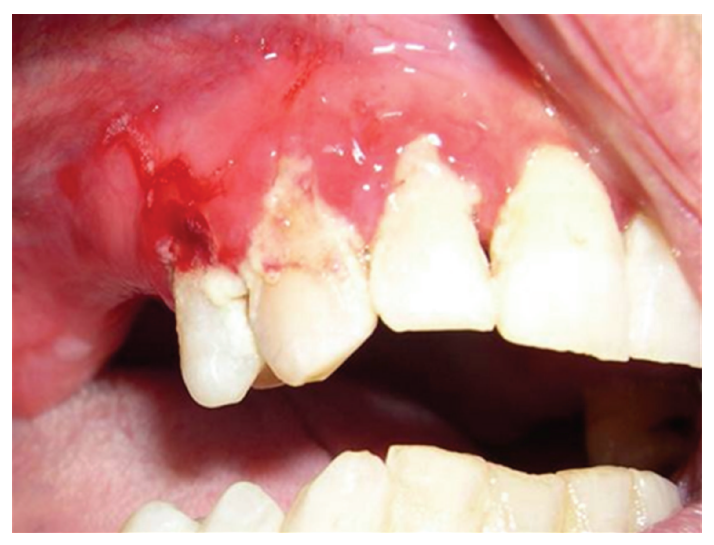

Figure 5: Periodontal disease.

Intrinsic Acids. They are derived from serious gastroesophageal reflux [16-18] (Figure 4).

\section{Periodontal Disease}

Periodontal disease evolves more quickly in undernourished populations: "...the pathology starts in the gum and could interest the periodontal ligament up to the alveolar bone...". The most important risk factor in the development of periodontal disease is represented by inadequate oral hygiene (Figure 5). Data supplied by the National Health and $\mathrm{Nu}-$ trition Examination Survey 2001/02 underlined that a low level of folic acid is associated to periodontal disease. The serum level of folates is an important index of periodontal disease and can represent an objective that should be pursued in the promotion of periodontal health [19].

Malnutrition and bad oral hygiene represent two important factors that predispose for necrotizing gingivitis. Prevention programs against disease must therefore include a correct evaluation of the immune system and the promotion of nutritional programs. The aim of nutritional support in inflammatory diseases is to provide the right energy and 


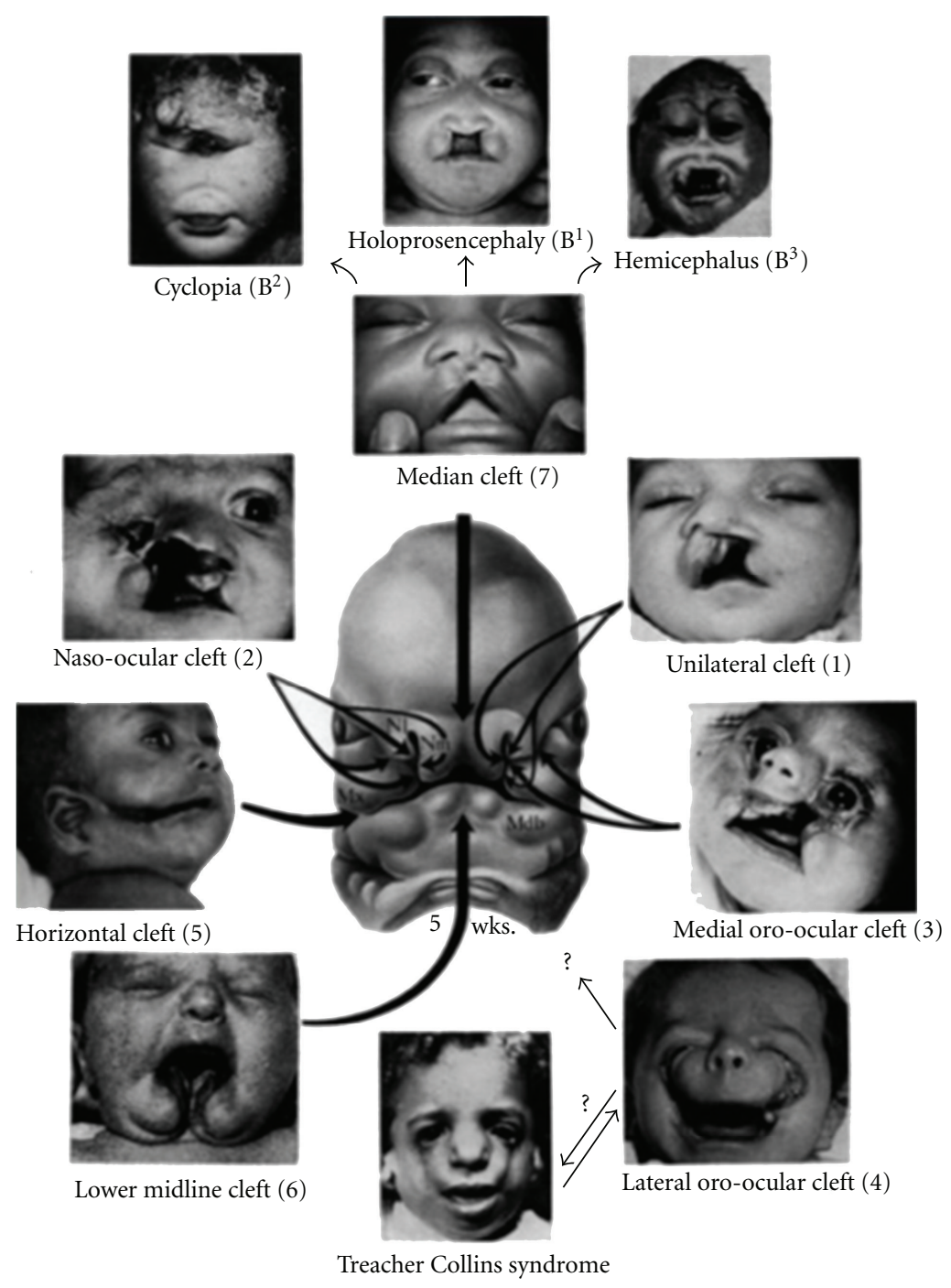

FIgURE 6: Cleft lip and palate.

nourishment to respond to the increased demand for protein synthesis in the acute phase, inflammatory mediators, antioxidant defence mechanisms, as well as for the promotion of tissue reparation. Some nutrients have a very important role in the resolution of the inflammatory process. These observations confirm the relationship between diet and periodontal disease [20]. In a recent interview, the president of the American Society of Periodontology, Michael P. Rethman [20], underlined the importance of diet for a healthy smile. In particular, the correlation between the income of calcium and periodontal disease can be due to the role that calcium has in the density of the alveolar bone that supports teeth. Also the intake of vitamin C is fundamental for maintenance and for the activation of reparative mechanisms thanks to its antioxidant properties [20].

Noma is an orofacial gangrene originating in the gingival-oral mucosa [21]. Although cases of noma are now rarely reported in the developed countries, it is still prevalent among children in third world countries, notably in subSahara Africa, where malnutrition and preventable childhood infections are still common [21]. Noma can be prevented through promotion of national awareness of the disease, poverty reduction, improved nutrition, promotion of exclusive breastfeeding in the first 3-6 months of life, optimum prenatal care, and timely immunisations against the common childhood diseases [21].

\section{Gene Disease}

Italian researchers have recently identified the genetic defect responsible for cleft lip and palate (Figure 6). The gene is a variation of the maternal gene "MTHFR" that determines the lowering of folate levels in blood. The female carriers of the discovered mutation have a greater risk of giving birth to children affected by cleft lip and palate. Folate is fundamental in the first phases of embryonic development: in fact the lack of this vitamin is able to cause defects in the embryonic development known generically as "defects of the neural tube". For this reason, in the United States B9 is 


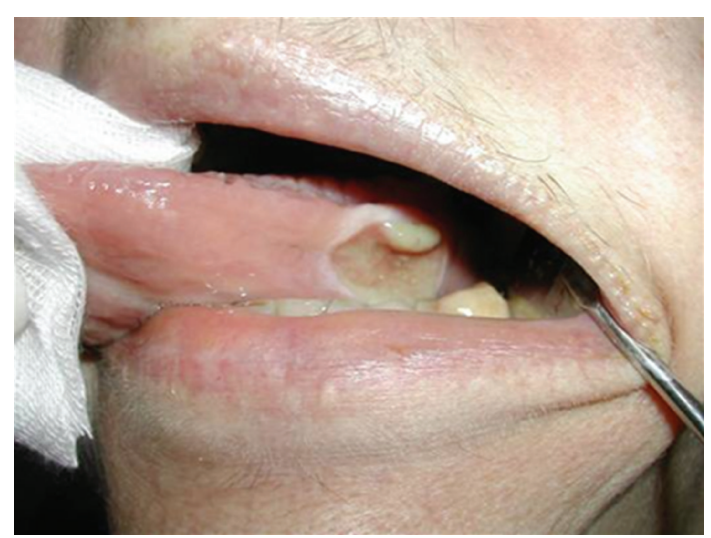

FIgURE 7: Oral cancer.

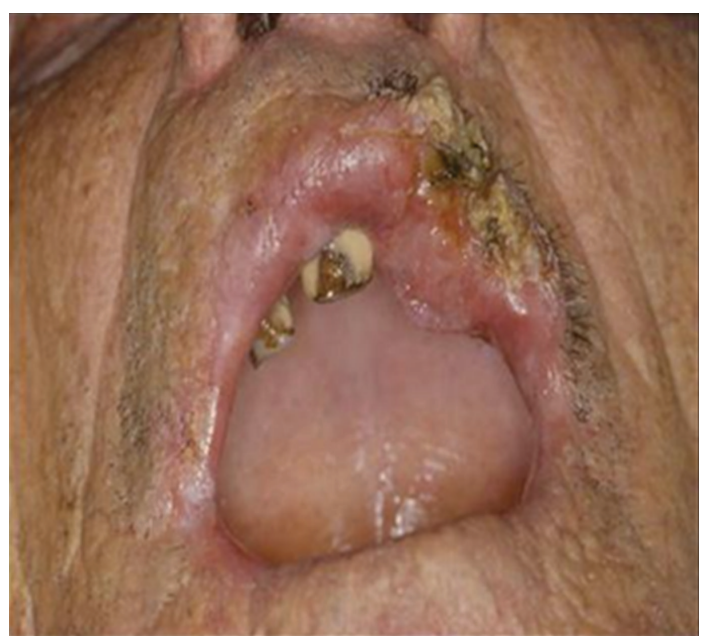

Figure 8: Oral cancer.

administered with the support of the health authorities to women who are intend to conceive and in the first months of pregnancy. Administering folate in the months preceding conception and in the first months of pregnancy, the risk of defects to the nervous system is reduced and even cleft lip and palate could be avoided with the preventive administration of the vitamin [22].

\section{Neonatal Diet and Oral Health}

The World Health Organization and the American Pediatric Association have shown that breast feeding influences lingual deglutition, the growth of the maxillae and the correct alignment of the teeth, as well as the modelling of the hard palate. Vice versa, bottle feeding the baby influences the formation of the ogival palate as well as the formation of "crossbite", a reduced opening of the back nasal cavity, and an increased incidence of sleep apnea. In addition, artificial feeding influences the possibility of the onset of arterial hypertension, obesity, cardiovascular illnesses, and inflammatory pathologies regarding oral mucous $[23,24]$.

\section{Oral Cancer}

The association between diet and oral cancer is extremely serious. It is a pathology that is diagnosed in three hundred

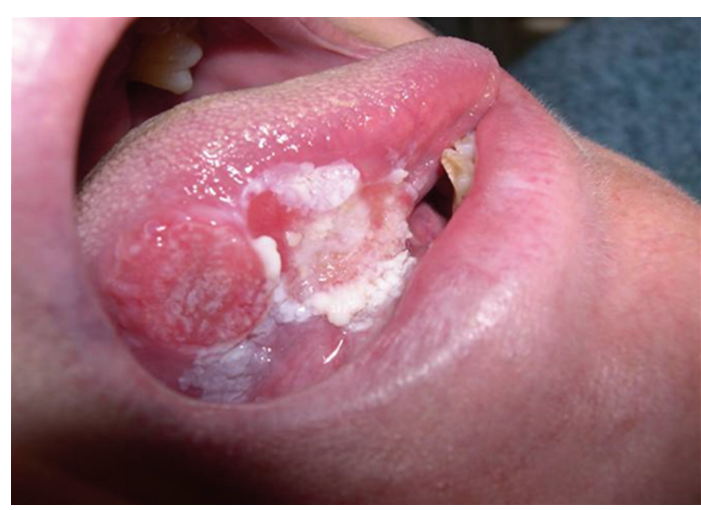

Figure 9: Oral cancer.

thousand new cases in the world every year and presents the greatest incidence in people who smoke, chew tobacco, and consume alcohol (Figures 7, 8, and 9).

The use of tobacco can alter the distribution of nutrients such as antioxidants, which develop a protective action toward the cells: smokers present levels of carotenoids and vitamin $\mathrm{E}$ in the blood that are superior to those in the oral mucous and, in addition, have a different distribution in comparison to the norm; the levels of folates in the blood and in the cells of the oral tissues of smokers are inferior to those of nonsmokers; the inside of the cheeks of smokers presents numerous micronuclei (modifications typical of pre- and neoplastic lesions) $[25,26]$. The study of the incidence of this illness has underlined the possibility that diet can represent an important etiological factor for oral carcinogenesis. Vitamins A, E, C, and Beta Carotene have antioxidant properties.

(i) They neutralize metabolic products.

(ii) They interfere with the activation of procarcinogens.

(iii) They inhibit chromosomal aberration.

(iv) They potentially inhibit the growth of malignant lesions (leukoplakia).

The mechanism that connects smoke to this disease has not been discovered but some progress has been made: smoke modifies the distribution of protective substances such as folates and some antioxidants. A rebalancing of nutrients obtained through diet can modify the altered distribution caused by the consumption of tobacco. In an imbalanced diet there is a depletion of antioxidant nutrients. Fruit and vegetables have, vice versa, important antioxidant properties. Many micronutrients (vitamins in particular) are used in chemoprevention programs formulated by the US National Cancer Institute [27].

The National Cancer Institute and the American Cancer Society have established some prudential dietary recommendations for the choice of food:

(1) maintain a desirable body weight,

(2) eat a varied diet,

(3) include a new variety of fruits and vegetables in the daily diet, 
(4) consume a greater quantity of foods rich in fibre,

(5) decrease the total intake of fats $(30 \%$ less than the total calories),

(6) limit the consumption of alcohol,

(7) limit the consumption of salted food or food preserved with nitrates.

In patients with an advanced tumour disease, protein-caloric malnutrition is a recurrent problem due to factors such as a form of anorexia that is established, maldigestion, malabsorption, and to a difficulty in mastication and deglutition [26]. Foods should be provided that aim to correct nutritional deficits and ponderal reduction when consumed in a large enough quantity to cover protein and caloric requirements. Malnutrition also interferes negatively with humoral and cellular immunocompetence and with tissue and reparative functions. In addition, the alteration of the liver function can change the way drugs are metabolized. Therefore, malnutrition can interfere with oncological therapy and increase the severity of the collateral effects [25].

Some studies show a small effect of dietary supplementation on cancer incidence, while others show that supplementation with antioxidant vitamins may have an adverse effect on the incidence of cancer and cardiovascular diseases or no effect [27].

Increasing attention has been given to the potential protective roles of specific antioxidant nutrients found in fruits and vegetables.

In a recent research El-Rouby showed that lycopene can exert protective effects against 4-nitroquinoline-1-oxide induced tongue carcinogenesis through reduction in cell proliferation and enhanced cellular adhesion, suggesting a new mechanism for the anti-invasive effect of lycopene [28].

In a recent report Edefonti et al. showed that diets rich in animal origin and animal fats are positively, and those rich in fruit and vegetables and vegetable fats inversely related to oral and pharyngeal cancer risk [29].

\section{Oral Candidosis}

A significant correlation has been evinced with a lack of iron (Figure 10). This causes alterations in the epithelium with consequent atrophy and alteration in cellular turnover, an alteration in the iron-dependent enzymatic system depression in cell-mediated immunity, phagocytosis, and in the production of antibodies. The correlation between candidiasis and the lack of folic acid, vitamins A, B1, B2, vitamins $C, K$, zinc, and a diet rich in carbohydrates is also significant [30].

\section{Potentially Malignant Oral Lesions}

These are those pathologies of the oral mucous (oral lichen planus, leukoplakia) that present a tendency for malignant degeneration if some favourable conditions persist (Figure 11). There are conflicting data in literature regarding levels of retinol and beta carotene and the onset of oral lichen planus [31]. Ramaswamy et al. affirmed that folate levels should be investigated in patients with oral lesions

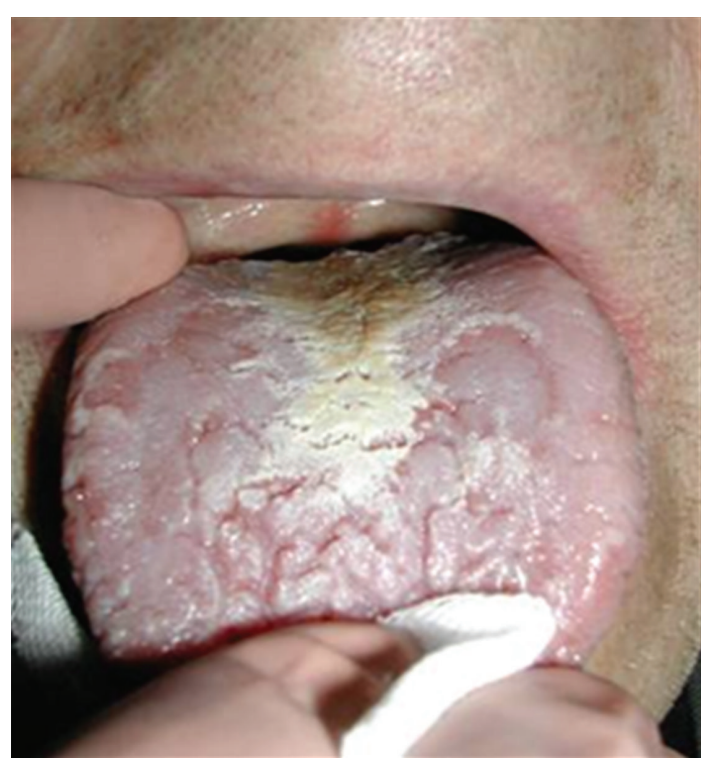

FIgURE 10: Oral candidosis.

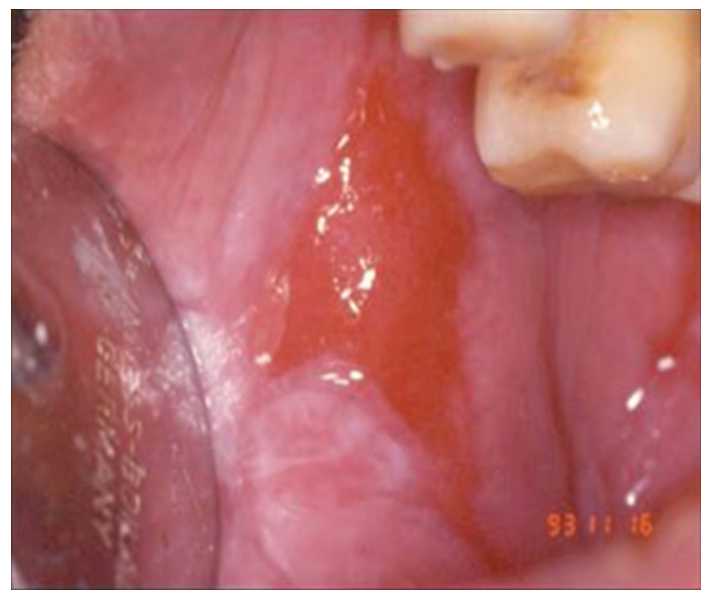

FIgURE 11: Oral lichen planus.

and symptoms especially those with risk factors of age, poor nutrition, or systemic diseases. When suspected, daily folic acid supplements should be given [32].

With regard to leukoplakia, a significant association has been found with reduced serum levels of vitamins A, C, and B12, and folic acid (Figure 12). Data in literature confirm that diets rich in fruit and vegetables, above all tomatoes and products derived from them, significantly reduce the risk of the onset of leukoplakia [33]. In a recent report Lodi et al. said that treatment with beta carotene and vitamin A or retinoids was associated with better rates of clinical remission, compared with placebo or absence of treatment. Treatments may be effective in the resolution of lesion; however, relapses and adverse effects are common [34].

\section{Micronutrient Deficiencies and Mucosal Disorders}

Various types of nutritional deficiencies can produce oral mucosal diseases. Changes such as swelling of the tongue, 


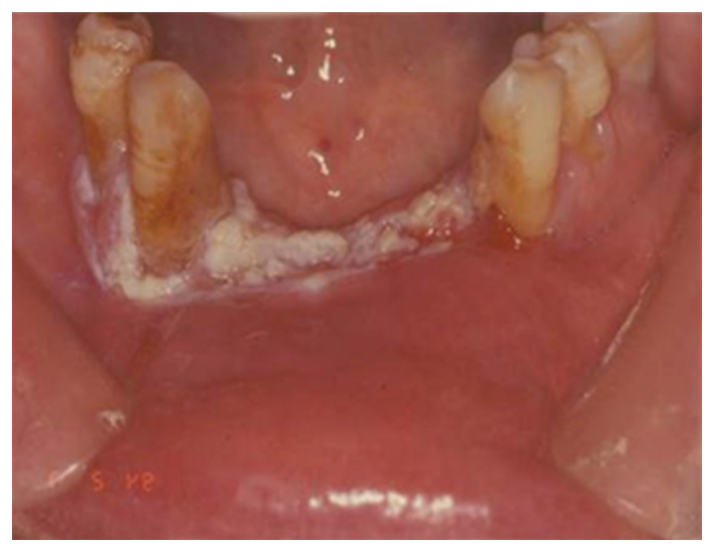

FIGURE 12: Oral leukoplakia.

papillary atrophy, and surface ulceration are possible in case of micronutrient deficiencies (iron, folate, vitamin B12) [35]. To establish iron, folate, or vitamin B12 deficiency, a hematologic screening that includes complete blood count, red-cell, serum iron, B12, and folate levels should be performed $[35,36]$. Although they are rarely required, specific tests for suspected niacin, pyridoxine, and riboflavin deficiency are available [35]. Although glossodynia related to nutritional deficiency is statistically uncommon, it is easily curable with replacement therapy [35]. Identification of a vitamin deficiency through early oral symptoms can forestall development of serious and irreversible systemic and neurologic damage [36]. Deficiencies of vitamin B12 can produce oral signs and symptoms, including glossitis, angular cheilitis, recurrent oral ulcer, oral candidiasis, and diffuse erythematous mucositis. Plummer Vinson syndrome is associated with glossitis and angular cheilitis $[35,36]$.

\section{References}

[1] G. Belcastro, E. Rastelli, V. Mariotti, C. Consiglio, F. Facchini, and B. Bonfiglioli, "Continuity or discontinuity of the lifestyle in central Italy during the Roman imperial age-early middle ages transition: diet, health, and behavior," American Journal of Physical Anthropology, vol. 132, no. 3, pp. 381-394, 2007.

[2] N. Dion, J. L. Cotart, and M. Rabilloud, "Correction of nutrition test errors for more accurate quantification of the link between dental health and malnutrition," Nutrition, vol. 23, no. 4, pp. 301-307, 2007.

[3] A. Singh, M. P. Bharathi, P. Sequeira, S. Acharya, and M. Bhat, "Oral health status and practices of 5 and 12 year old indian tribal children," Journal of Clinical Pediatric Dentistry, vol. 35, no. 3, pp. 325-330, 2011.

[4] Chicago Dental Society, "Good oral health starts with exercise, eating right," CDS Review, vol. 104, no. 2, p. 34, 2011.

[5] B. A. Dye, L. K. Barker, X. Li, B. G. Lewis, and E. D. Beltrán-Aguilar, "Overview and quality assurance for the oral health component of the National Health and Nutrition Examination Survey (NHANES), 2005-08," Journal of Public Health Dentistry, vol. 71, no. 1, pp. 54-61, 2011.

[6] G. A. Scardina and P. Messina, "Nutrition and oral health," Recenti Progressi in Medicina, vol. 99, no. 2, pp. 106-111, 2008 (Italian).
[7] G. Bang and T. Kristoffersen, "Dental caries and diet in an Alaskan Eskimo population,” Scandinavian Journal of Dental Research, vol. 80, no. 5, pp. 440-444, 1972.

[8] B. Olsson, "Dental health situation in privileged children in Addis Ababa, Ethiopia," Community Dentistry and Oral Epidemiology, vol. 7, no. 1, pp. 37-41, 1979.

[9] A. Scheinin and K. K. Mäkinen, "Turku sugar studies. An overview," Acta Odontologica Scandinavica, vol. 34, no. 6, pp. 405408, 1976.

[10] B. E. Gustafsson, "The Vipeholm dental caries study: survey of the literature on carbohydrates and dental caries," Acta Odontologica Scandinavica, vol. 11, no. 3-4, pp. 207-231, 1954.

[11] P. Lingström, J. van Houte, and S. Kashket, "Food starches and dental caries," Critical Reviews in Oral Biology and Medicine, vol. 11, no. 3, pp. 366-380, 2000.

[12] P. J. Moynihan, S. Ferrier, and G. N. Jenkins, "The cariostatic potential of cheese: cooked cheese-containing meals increase plaque calcium concentration," British Dental Journal, vol. 187, no. 12, pp. 664-667, 1999.

[13] N. Gordon, "Oral health care for children attending a malnutrition clinic in South Africa," International Journal of Dental Hygiene, vol. 5, no. 3, pp. 180-186, 2007.

[14] L. Lupi-Pégurier, M. Muller-Bolla, E. Fontas, and J. P. Ortonne, "Reduced salivary flow induced by systemic isotretinoin may lead to dental decay. A prospective clinical study," Dermatology, vol. 214, no. 3, pp. 221-226, 2007.

[15] A. Faggella, M. G. Guadagni, S. Cocchi, T. Tagariello, and G. Piana, "Dental features in patients with Turner syndrome," European Journal of Paediatric Dentistry, vol. 7, no. 4, pp. 165168, 2006.

[16] B. Kargul, E. Caglar, and A. Lussi, "Erosive and buffering capacities of yogurt," Quintessence International, vol. 38, no. 5, pp. 381-385, 2007.

[17] M. Kitchens and B. M. Owens, "Effect of carbonated beverages, coffee, sports and high energy drinks, and bottled water on the in vitro erosion characteristics of dental enamel," Journal of Clinical Pediatric Dentistry, vol. 31, no. 3, pp. 153-159, 2007.

[18] R. Huew, P. Waterhouse, P. Moynihan, S. Kometa, and A. Maguire, "Dental caries and its association with diet and dental erosion in Libyan schoolchildren," International Journal of Paediatric Dentistry, vol. 22, no. 1, pp. 68-76, 2012.

[19] Y. H. Yu, H. K. Kuo, Y. L. Lai, Y. H. Yu, H. K. Kuo, and Y. L. Lai, "The association between serum folate levels and periodontal disease in older adults: data from the National Health and Nutrition Examination Survey 2001/02," Journal of the American Geriatrics Society, vol. 55, no. 1, pp. 108-113, 2007.

[20] M. S. Al-Zahrani, "Increased intake of dairy products is related to lower periodontitis prevalence," Journal of Periodontology, vol. 77, no. 2, pp. 289-294, 2006.

[21] K. U. Ogbureke and E. I. Ogbureke, "NOMA: a preventable "Scourge" of African children," Open Dentistry Journal, vol. 4, pp. 201-206, 2010.

[22] A. Verkleij-Hagoort, J. Bliek, F. Sayed-Tabatabaei, N. Ursem, E. Steegers, and R. Steegers-Theunissen, "Hyperhomocysteinemia and MTHFR polymorphisms in association with orofacial clefts and congenital heart defects: a meta-analysis," American Journal of Medical Genetics, Part A, vol. 143, no. 9, pp. 952960, 2007.

[23] K. Mukhopadhyay, A. Narang, and R. Mahajan, "Effect of human milk fortification in appropriate for gestation and small for gestation preterm babies: a randomized controlled trial," Indian Pediatrics, vol. 44, no. 4, pp. 286-290, 2007. 
[24] S. Martignon, M. C. González, R. M. Santamaráa, S. JácomeLiévano, Y. Munoz, and P. Moreno, "Oral-health workshop targeted at $0-5-y r$. old deprived children's parents and caregivers: effect on knowledge and practices," Journal of Clinical Pediatric Dentistry, vol. 31, no. 2, pp. 104-108, 2006.

[25] L. Gould and S. Lewis, "Care of head and neck cancer patients with swallowing difficulties," British Journal of Nursing, vol. 15, no. 20, pp. 1091-1096, 2006.

[26] N. Taghavi and I. Yazdi, "Type of food and risk of oral cancer," Archives of Iranian Medicine, vol. 10, no. 2, pp. 227-232, 2007.

[27] L. Giovannelli, C. Saieva, G. Masala et al., "Nutritional and lifestyle determinants of DNA oxidative damage: a study in a Mediterranean population," Carcinogenesis, vol. 23, no. 9, pp. 1483-1489, 2002.

[28] D. H. El-Rouby, "Histological and immunohistochemical evaluation of the chemopreventive role of lycopene in tongue carcinogenesis induced by 4-nitroquinoline-1-oxide," Archives of Oral Biology, vol. 56, no. 7, pp. 664-671, 2011.

[29] V. Edefonti, F. Bravi, C. La Vecchia et al., "Nutrient-based dietary patterns and the risk of oral and pharyngeal cancer," Oral Oncology, vol. 46, no. 5, pp. 343-348, 2010.

[30] E. Paillaud, I. Merlier, C. Dupeyron, E. Scherman, J. Poupon, and P. N. Bories, "Oral candidiasis and nutritional deficiencies in elderly hospitalised patients," British Journal of Nutrition, vol. 92, no. 5, pp. 861-867, 2004.

[31] T. Nagao, S. Warnakulasuriya, N. Ikeda et al., "Serum antioxidant micronutrient levels in oral lichen planus," Journal of Oral Pathology and Medicine, vol. 30, no. 5, pp. 264-267, 2001.

[32] G. Ramaswamy, V. R. Rao, S. V. Kumaraswamy, and N. Anantha, "Serum vitamins' status in oral leucoplakias-a preliminary study," European Journal of Cancer Part B, vol. 32, no. 2, pp. 120-122, 1996.

[33] K. Thongprasom, P. Youngnak, and V. Aneksuk, "Folate and vitamin B12 levels in patients with oral lichen planus, stomatitis or glossitis," Southeast Asian Journal of Tropical Medicine and Public Health, vol. 32, no. 3, pp. 643-647, 2001.

[34] G. Lodi, A. Sardella, C. Bez, F. Demarosi, and A. Carrassi, "Systematic review of randomized trials for the treatment of oral leukoplakia," Journal of Dental Education, vol. 66, no. 8, pp. 896-902, 2002.

[35] D. M. Thomas and G. W. Mirowski, "Nutrition and oral mucosal diseases," Clinics in Dermatology, vol. 28, no. 4, pp. 426$431,2010$.

[36] R. Hefaiedh, Y. Boutreaa, A. Ouakaa-Kchaou et al., "PlummerVinson syndrome," Tunisie Medicale, vol. 88, no. 10, pp. 721724,2010 . 

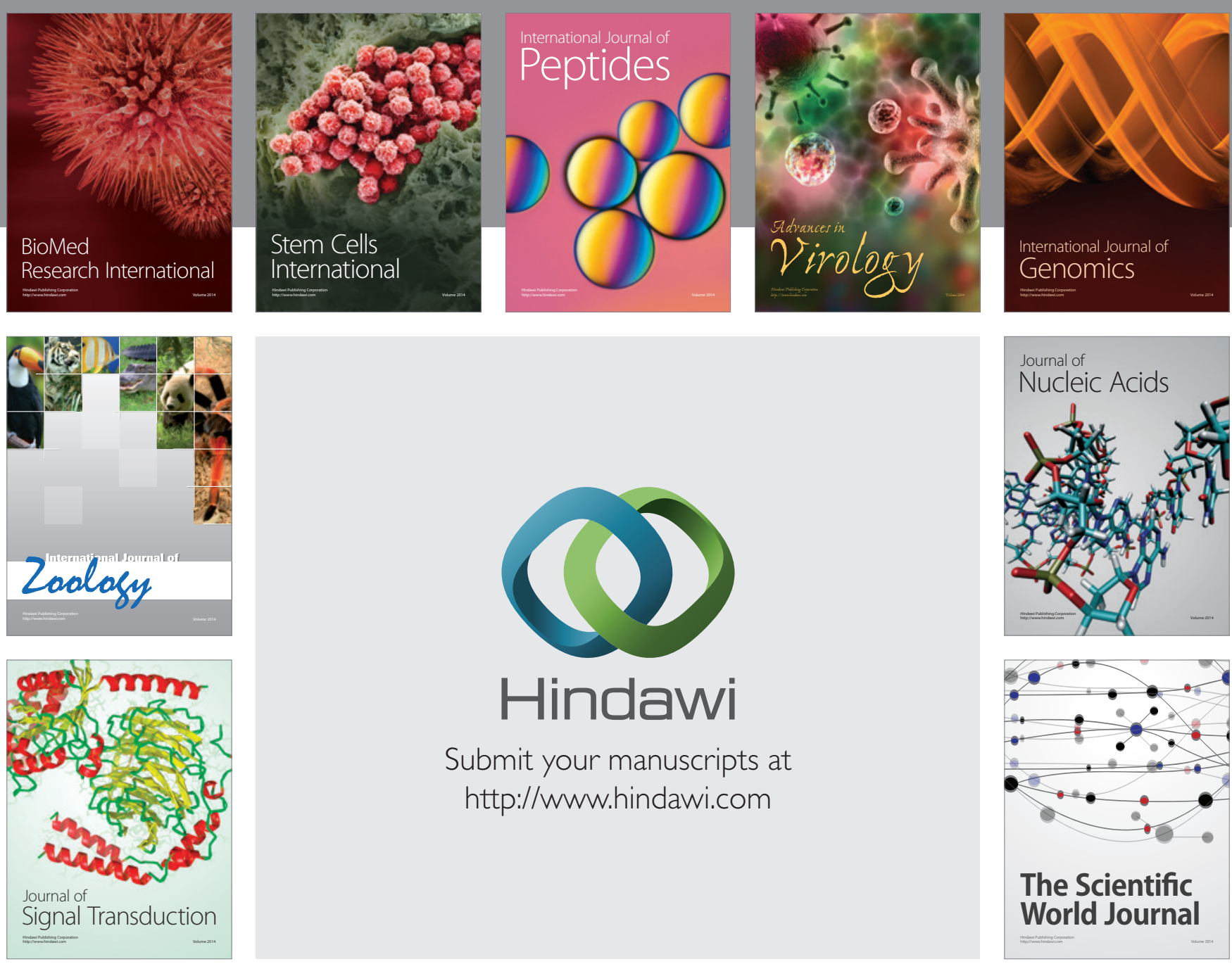

Submit your manuscripts at

http://www.hindawi.com
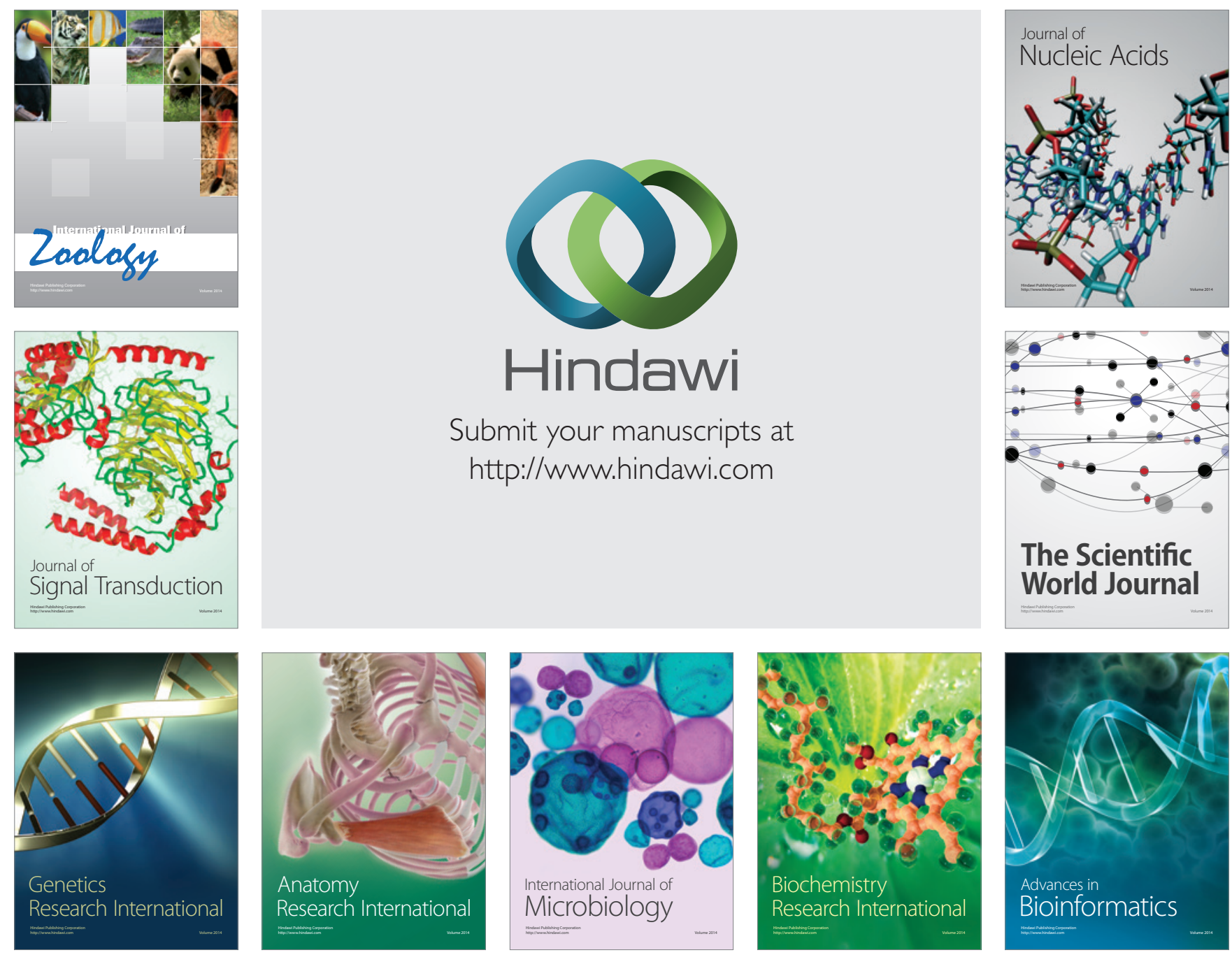

The Scientific World Journal
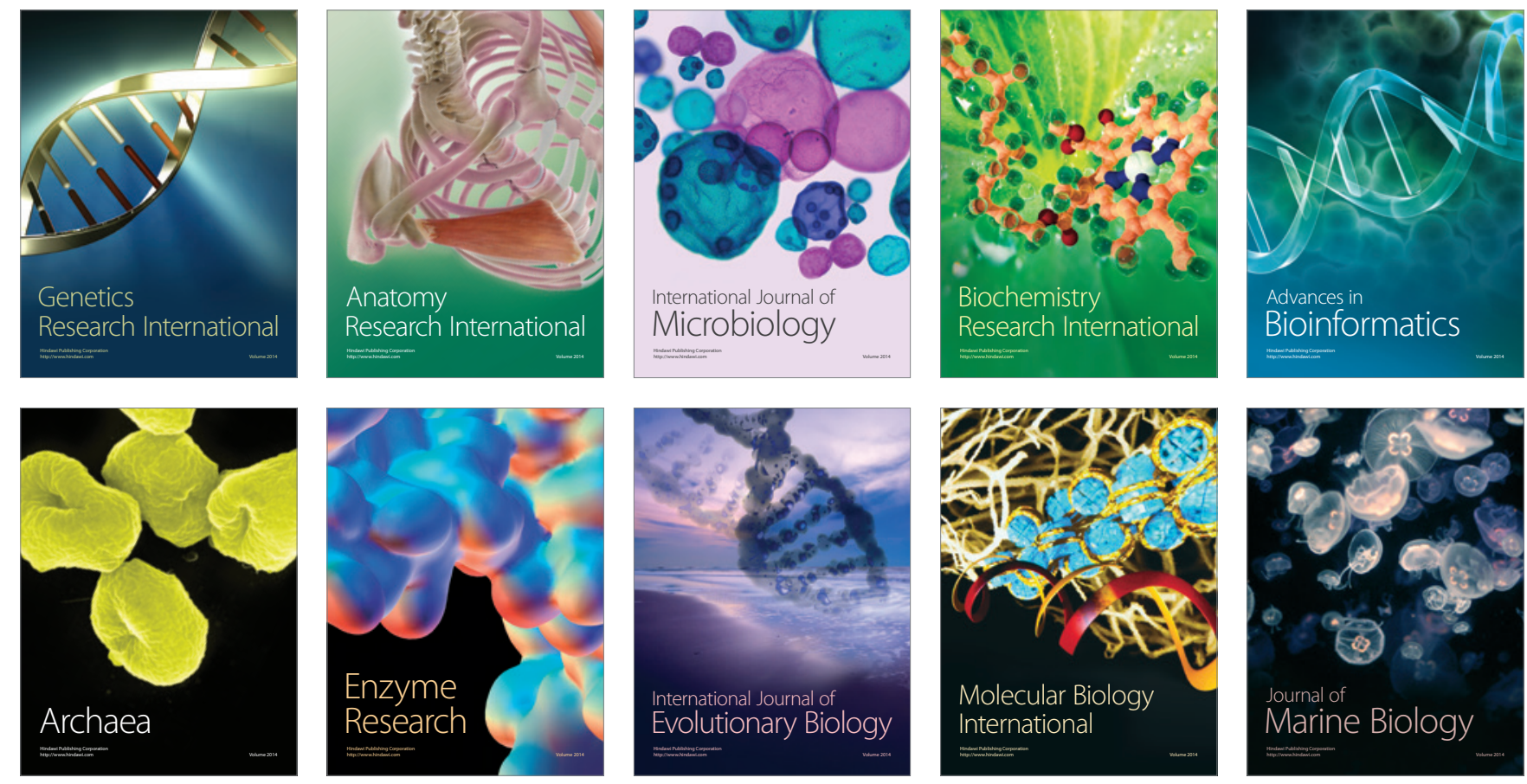